\title{
Implant mimicking cartilage for craniofacial reconstruction: A new material introduced for research
}

\author{
Biswajit Kumar Biswas $^{1 *}$, Anindya Chakrabarty ${ }^{2}$, Sutapa Dey $^{3}$, Biswajit Das ${ }^{4}$ \\ ${ }^{\mathbf{1} C}$ Consultant, ${ }^{2,4} \mathrm{MDS}$ (Cal), ${ }^{\mathbf{3}}$ Research Fellow, Dept. of Oral \& Maxillofacial Surgeon, Avinash Institute of Craniofacial \& Reconstructive \\ Surgery, West Bengal, India \\ *Corresponding Author: Biswajit Kumar Biswas \\ Email: doc135798@yahoo.co.in
}

\begin{abstract}
Loss of facial structure as a consequence of injury or salvaging surgery, demands reconstruction and rehabilitation of lost structures. Here comes the role of a reconstructive and craniofacial surgeon. Lots of surgical options are available to fulfil the requirement but all require a second operative site to restore the primary defect. New age of scientific development are in search of regenerate the lost structures by the means of stem cell or biocompatible material. In such search we have tried to contribute by development of implant mimicking cartilage to reconstruct the lost facial structure. In this article we are going to share our research experience, to fulfil our goal and objective we have developed three different types of biocompatible silicon material ( $\mathrm{Si}-40, \mathrm{Si} 60$ \& Si80). After formulation, preparation and mechanical characterization, it was observed that $\mathrm{Si} 40$ was best suitable silicone for bio-composite preparation.
\end{abstract}

Keywords: Reconstructive, Cartilages, Implantable.

\section{Introduction}

Craniofacial and maxillofacial surgeons are frequently tasked to perform reconstructive surgery in the setting of trauma, congenital deformity, or malignancy. Cartilage posses little innate ability for repair and regeneration. Therefore cartilage loss in the head and neck region leads to permanent loss of structure and function. ${ }^{1}$ Clinically, reconstructive surgery has arrived at a standard of care that allows for repair and restoration of the vast majority of tissues/organs with established techniques. The real challenge of tissue engineering in clinical treatment is the reduction of surgical morbidity by the application of biological signals or bio-artificial components cultivated from the patient's own cells, that can replace the lost body parts or accomplish its repair without the need for autogenous tissue transfer. ${ }^{2}$ Cartilage was one of the first tissues to be investigated in early tissue engineering efforts. ${ }^{3}$ We are in search of implantable biocompatible materials mimicking cartilages to reconstruct the facial tissue with minimum morbidity or deleterious host-implant reaction.

The aim of the project is to develop a new biocompatible cartilage like materials to restore the anatomical form and function and to improve social confidence and quality of life.

\section{Objective of the Project}

1. Selection of Pure silicon as raw material with specific hardness value.
2. Standardization of new composite material with different ingredients suitable for the particular uses.

3. Preparation of Biocomposites in different concentration with different bio-materials.

4. Sterilization of the composite material done by autoclave.

5. Preparation of 12 Biocomposites and finding out the Mechanical characterizations of newly formed composite materials.

\section{Materials and Methods}

To full fill our study we have procured industrial grade silicon (Si 30, 40, 90) from market. Those material blended with bio-inert medical grade silicon and bio active materials (calcium hydroxyapatite [HAP] \{prepared in following manner: Extracted teeth collected, cleaned and inserted into the heated Muffle furnace. The heated teeth will be collected from the muffle furnace and placed inside the ball mill. Calcium phosphate powder is produced from the Teeth using Ball mill.\}, bio-glass, titanium oxide $\left[\mathrm{TiO}_{2}\right]$ with different combination [Si 95\%, $\mathrm{TiO}_{2} 1 \%$, HAP 4\%]. All the materials blended by mixing mill until the mixture seems like a homogenous one. Dice of desired shape were pre heated for 1 hour at $90^{\circ} \mathrm{C}$. Homogenous mixture of silicon \& desired material placed on the dice and put under the screw mil with slice heater to heat at $80^{\circ} \mathrm{C}$ for $10 \mathrm{~min}$. After that the procured material put in to incubator at $100^{\circ} \mathrm{C}$ until the ordure of the material removed.

The formed material then cut into desired shape and subjected to physical analysis and further characterisation. 

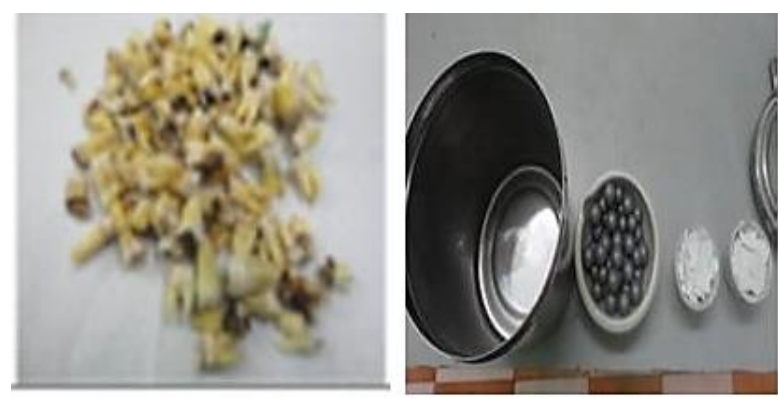

Fig. 1: Procuring hydroxyapetite from extracted tooth

\section{Preparation of Silicon based Bio composites}

We have prepared 12 empirically selected medical grade silicone based materials reinforced with easily available bioactive molecule like Hydroxyapatite and Titanium dioxide for development of biocompatible implant material mimicking craniofacial cartilage.

\section{Mechanical characterization}

This study aims to develop implants that would mimic the mechanical strength of human cartilage where goat ear is kept as benchmark for evaluation of mechanical parameters. In order to determine the parameters like tensile strength, Young's modulus, elongation at break, toughness; the stress-strain curve was obtained under $0.5 \mathrm{KN}$ load and at an extension rate of $3 \mathrm{~mm} / \mathrm{min}$. Stress strain curve generated by software (Emperor force testing system, version 1.18-408 $15 / 10 / 13$.) gives the information like yield strength, elastic limit, ultimate strength etc. From this information some parameters such as Young's modulus, \% Elongations can be calculated using different formula. Tensile strength of the each material was calculated by Peak load divided by total area of the test material. \% Elongation was determined by dividing maximum elongation of the material by initial length of the material. Hardness of the test material was determined by Shore A Durometer. Mechanical characterizations of the bio composites were evaluated using Mecmesin Multi test -I instrument keeping goat ear as benchmark as some literature have showed similar mechanical properties of human cartilage with goat cartilage. Surface roughness of the bio composites were examined by Atomic force microscopy (AFM).

\section{Discussion}

Implants shorten reconstruction, reduce trauma for the patients, are, in principle, of unlimited availability and can be given definable qualities that outnumber those of biological transplants. However, transplants obviously cannot be regarded as ideal either because they often involve the necessity of a second intervention for removal, they are only available to a limited extent and some are at risk of postoperative deflection, shrinkage and absorption. ${ }^{4}$ The use of implantable alloplastic biomaterials has become an integral part of facial reconstructive and aesthetic surgeries due to their efficiency and ease of use..$^{5}$ Today's plastic surgeons are frequently confronted with requests for alterations in facial profile for a variety of reasons:
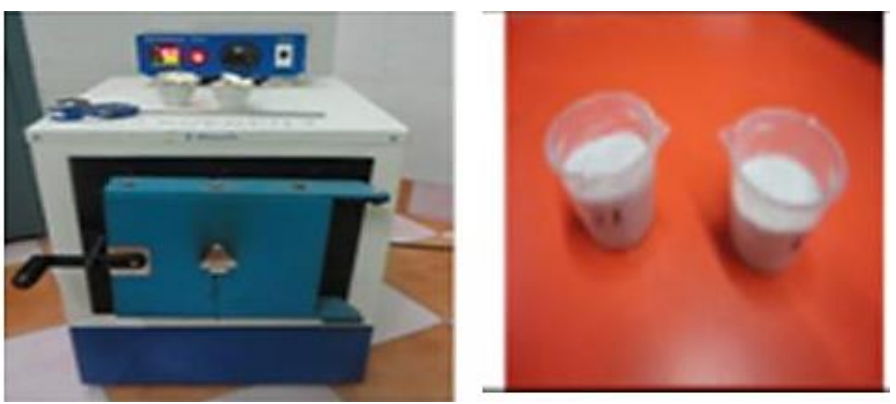

congenital, oncologic, post-traumatic or purely cosmetic considerations. Two of the most popular implant materials used today are Polyethylene (Medpor) and Silicone. Brandt and Moore performed a review of the literature in 2013 on implants used exclusively for aesthetic facial augmentation and reported that the study of facial implants had waned in recent years. ${ }^{6}$ Before that, in 1997, Rubin and Yaremchuk performed an extensive review of complications and toxicities of implantable biomaterials used in facial reconstructive and aesthetic surgeries. ${ }^{5}$ A preferred use of Medpor over Silicone for facial implantation over the last 20 years has been evident through studies. Silicone was developed in the 1950s and Medpor was developed in the early 1970 s. $^{7}$

Medpor is manufactured from linear high-density polyethylene through the process of sintering in which small particles are fused together at high temperature and pressure, so that it is composed of $50 \%$ porous volume with pore sizes ranging from 100 to $250 \mu \mathrm{m}$. This allows maximum fibrous tissue in growth and relative incorporation into host tissue. ${ }^{8}$ This property represents its primary strength but also its greatest weakness. ${ }^{9}$ Medpor implant causes thinning of the overlying skin envelope and although the implant becomes densely adherent to the surrounding soft tissue, it does not bond with the underlying bone or cartilage firmly enough and hence mild mobility is always a problem. ${ }^{10}$ These implants have high infection (3$4 \%$ ) and extrusion rates, ranging from $3.1 \% .{ }^{11}$ to as high as $21 \%^{12}$ and often require removal, which can be extremely difficult because of tissue incorporation. ${ }^{13}$ Explanation surgery is treacherous as there is a high incidence of button holing, thinning, and irregularity of overlying skin and damage to surrounding structures.

To overcome such short comes we have tried to prepare some cartilage like biomaterials from medical grade liquid silicon amalgamated with raw silicon (Si 40,60), hydroxy apetite and titanium oxide. As per a preclinical study performed in USA in 2006 to compare several animal cartilage to human cartilage ${ }^{14}$ shows that horse cartilage provides the closest approximation to man in terms of articular cartilage thickness ${ }^{15}$ and goat is the next animal after the horse which comes close to the size of human articular cartilage thickness. ${ }^{16}$ Depending on the easy availability we have chosen goat cartilage as the standard of gradation for our study. 


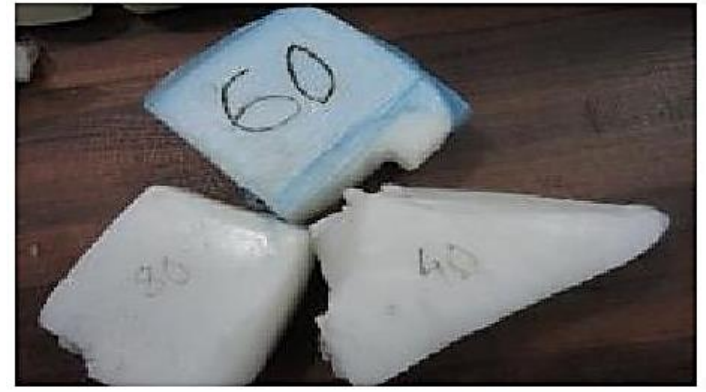

Raw silicone

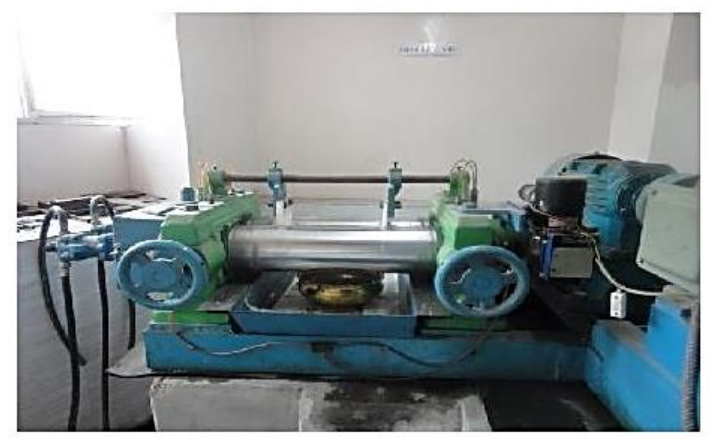

Mixing mill

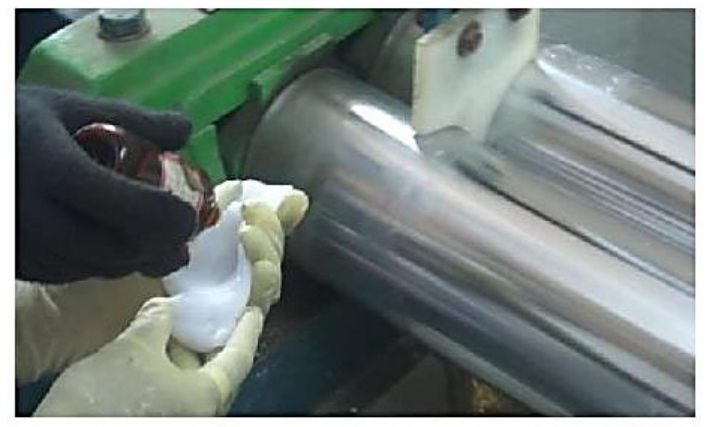

Silicone mixing

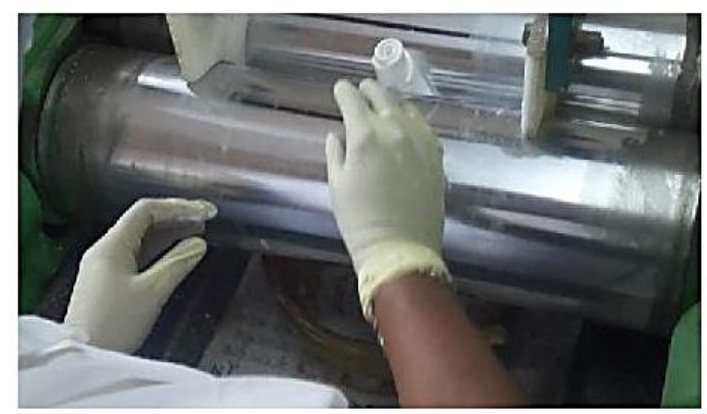

Rolling in mixing mill

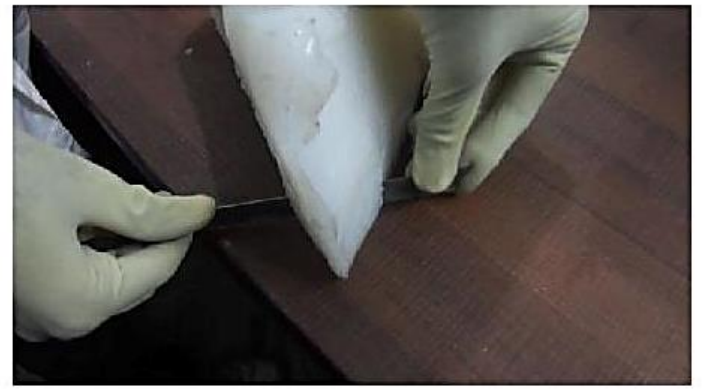

Cutting silicone

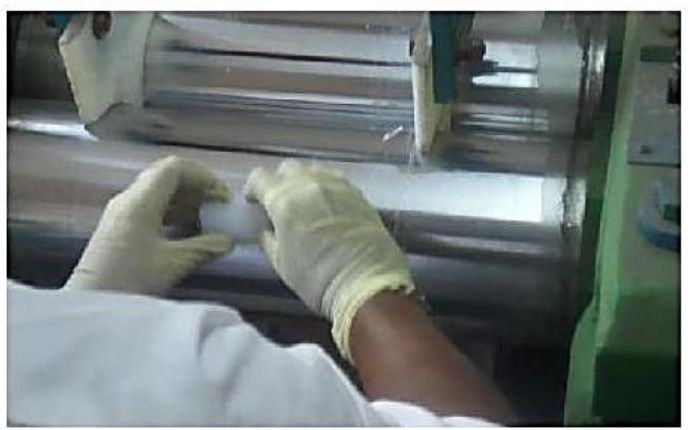

Bioactive material mixing with silicone

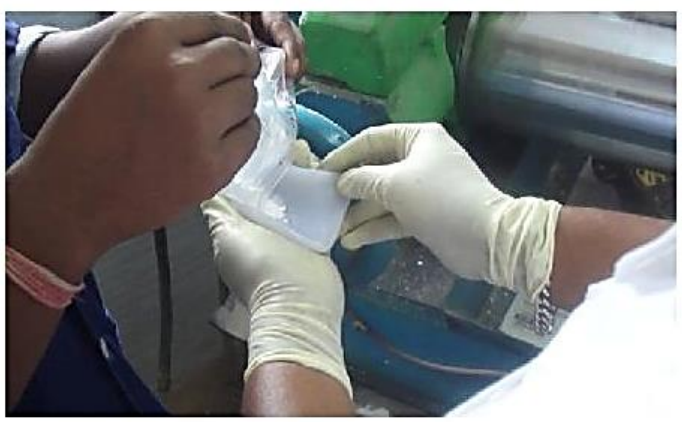

Curing

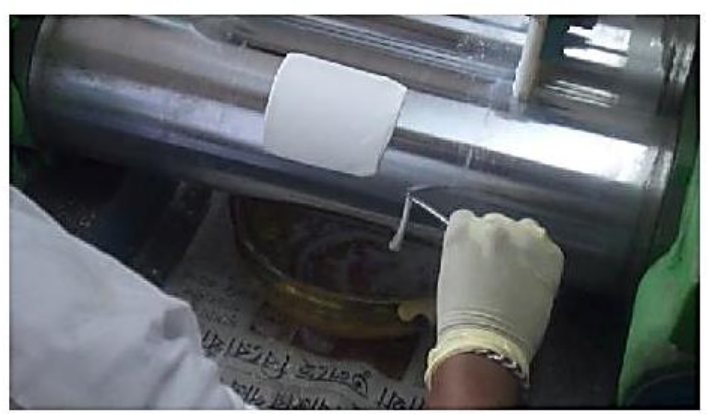

Sizing the material

Fig. 2: Stepwise process of preparation of biocomposite 


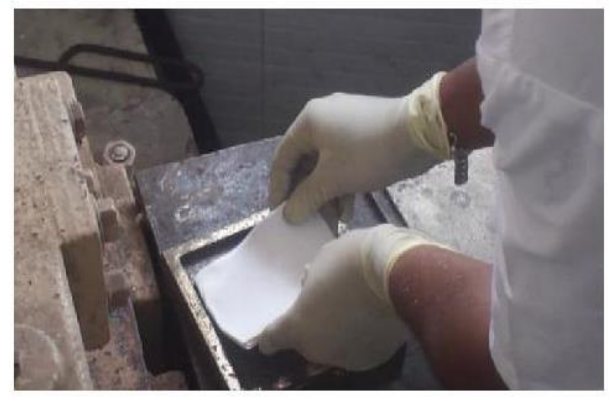

Placement of material in dice

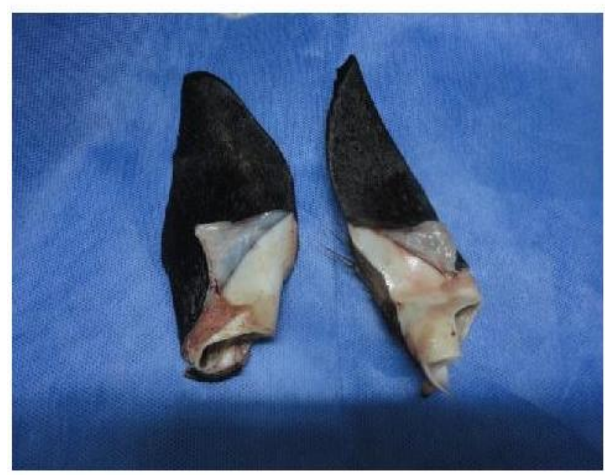

Goat Ear

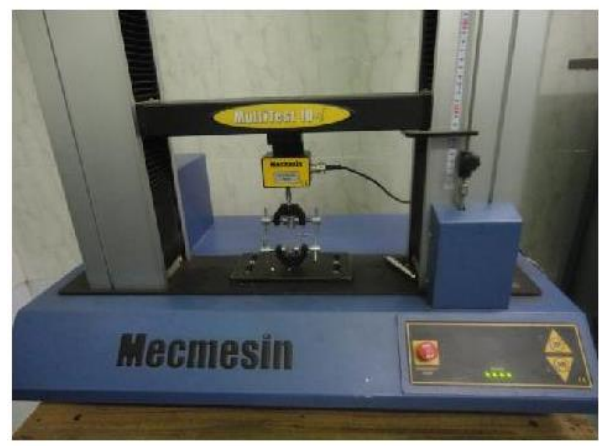

Mecmesin

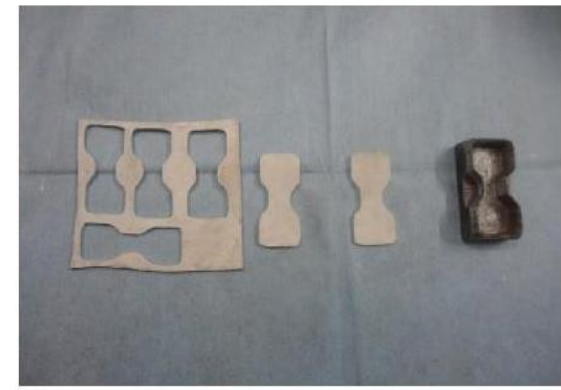

Preparation of dumbbell shaped material

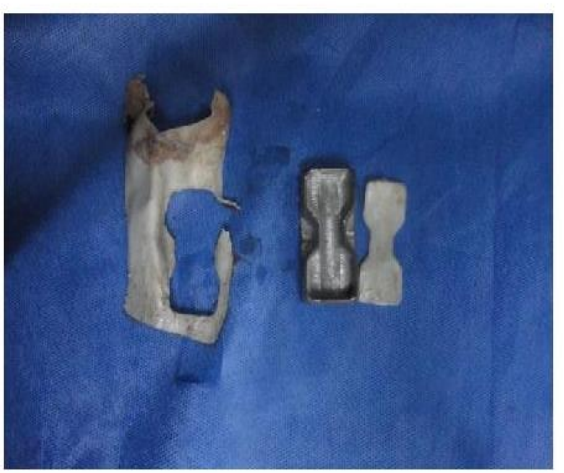

preparation Dumbell shaped goat ear

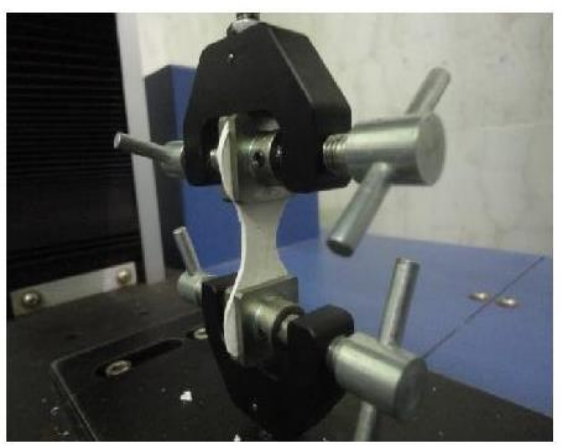

Mechanical testing in M ecmesin

Fig. 3: Preparing different shape form bio composite, procuring goat cartilage, checking mechanical properties

Further in vivo and in vitro studies is under progress.

Ethical Committee clearance: Institutional clearance taken.

\section{Acknowledgement}

1. Project funding - BIRAC (Biotechnology Industry Research Assistance Council) under BIPP (Biotechnology Industry Partnership programme) Scheme,

2. Department of Zoology, Barasat Government College for technical support.

3. Department of Physics, Jadavpur University for Scanning Electron Microscopy (SEM).
4. Indian Association for the cultivation of science, Department of Central Scientific Service for Atomic Force Microscopy (AFM)

\section{Source of funding}

None.

\section{Conflict of interest}

None. 


\section{References}

1. Singh Madhumati, Chakrabarty Anindya. Tissue Engineering for Orofacial Region. LAP 1AMBERT academic Publishing, 2017.

2. Alsberg E, Hill EE and Mooney DJ. Craniofacial tissueengineering. Crit Rev Oral Biol Med 2001;12:64-75.

3. la., Peer. The neglected septal cartilage graft, with experimental observations on the growth of human cartilagegrafts. Arch Otolaryngol 1945;42:384.

4. Berghaus, Alexander. Implants for reconstructive surgery of the nose and ears. Otorhinol Head Neck Surge 2007;6.

5. MJ., Rubin JP and Yaremchuk.Complications and Toxicities of Implantable Biomaterials Used in Facial Reconstructive and Aesthetic Surgery: A Comprehensive Review of theLiterature. Plast Reconstr Surg 1997;100:1336-53.

6. CC., Brandt MG and Moore. Implants in Facial Skeletal Augmentation. Curr Opin Otolaryngol Head Neck Surg 2013;21:396-9.

7. S.Frodel JL and Lee. The Use of High-Density Polyethylene Implants in Facial Deformities. Arch Otolaryngol Head Neck Surg 1998;124:1219-23.

8. Spector M, Flemming WR, Sauer BW. Early tissue infiltrate in porous polyethylene implants into bone: a scanning electron microscope study. J Biomed Mater Res 1975;9:537-42.

9. Kapil Agrawal, Raghav Shrotriya. Management of complications of Medpor ${ }^{\circledR}$ implants in rhinoplasty. Plast Aesthet Res 2017;4:54-6.

10. Cenzi R, Farina A, Zuccarino L, Carinci F. Clinical outcome of 285 Medpor grafts used for craniofacial reconstruction. $J$ Craniofac Surg 2005;16:526-30.
11. Peled ZM, Warren AG, Johnston P, Yaremchuk MJ. The use of alloplastic materials in rhinoplasty surgery: a meta-analysis. Plast Reconstr Surg 2008;121:e85-92.

12. Kim HS, Park SS, Kim MH, Kim MS, Kim SK, Lee KC. Problems associated with alloplastic materials in rhinoplasty. Yonsei Med J 2014;55:1617-23.

13. Chaudhury N, Marais J. Use of porous polyethylene implants in nasal reconstruction. Clin Rhinol 2011;4:63-70.

14. D. D. Frisbie, M. W. Cross, C. W. McIlwraithv. A comparative study of articular cartilage thickness in the stifle of animal species used in human pre-clinical studies compared to articular cartilage thickness in the human knee. Vet Comp Orthop Traumatol 2006.

15. Schachar NS, Novak K, Hurtig M. Transplantation $\mathrm{f}$ cryopreserved osteochondral Dowel allografts for repair of focal articular defects in an ovine model. J Orthop Res 1999;17:909-19.

16. Dreisang IMK, Hunziker EB.Delamination rates of tissue flaps used in articular cartilage repair. J Orthop Res 2000;18:909-11.

How to cite this article: Biswas BK, Chakrabarty A, Dey S, Das B. Implant mimicking cartilage for craniofacial reconstruction: A new material introduced for research. $J$ Oral Med, Oral Surg, Oral Pathol, Oral Radiol 2019;5(3):72-6. 